\title{
Syllable Structure of Oromo (Harar dialect) Based on Moraic Approach
}

\author{
Jamaica Kebede Dengela \\ Department of Amharic Language and Literature College of Social Science and Humanities, Madda Walabu \\ University, Bale Robe, Ethiopia
}

\begin{abstract}
This concept focused on the syllable structure of Oromo (Harar dialect) based on moraic theory. Based on this concerned idea, it has attempted to describe the syllable types that occur in Harar Oromo. These are CV, CVC, CVV, and CVVC syllables. Therefore, based on the notion of the moraic theory, the language assigned CV and CVC syllables as light, whereas CVV and CVVC syllables as heavy. In connection with light and heavy syllables, it has revealed that mono-moraic syllable as light, while bi-moraic and tri-moraic syllables as heavy in Oromo (Harar dialect). In these types of syllables, in addition to vowels (short and long), consonant geminates and clusters bear only one mora in word-medial position. In Harar Oromo, word-initial and final consonant gemination and cluster are not allowed. In the language, each word has initial consonant in underlying representation. However, in surface representation onset-less words are presented due to the deletion of the voiceless glottal plosive sound $/ \mathrm{P} /$. Due to this fact, some words begin with the vowel /i//, /e/,/u/,/o/and /a/ in the language. However, because of the derivation of surface structure from the underlying representation, onset consonants are obligatory constituents. Keywords: Phonology, Syllable Structure, Moraic theory, Harar Oromo, light and heavy syllables, and gemination and cluster.
\end{abstract}

DOI: $10.7176 / \mathrm{JLLL} / 71-01$

Publication date:August $31^{\text {st }} 2020$

\section{Introduction}

The people call themselves Oromo and are the major linguistic group in Ethiopia. They live over a large area "stretching from close to the Sudan border in the West, through Addis Ababa, and beyond Harar in the East, from Northern Kenya in the south, up East of the rift valley, and to Wallo in the north" (Gragg 1982: xiii). According to the 2007 population and housing census of Ethiopia, the population size of Oromo is 27,158,471 (37.7\%) out of the 73,918,505 total population of Ethiopia.

The primary economic activities of the people are agriculture and animal husbandry. Agriculture includes the production of coffee, grain, spice, vegetable and so forth. Mining, tourism, medium and small-scale industries etc are also par of the economy (http://en.Oromia.org/). The Ethiopian Oromo practice three different religions. These are Waaqqefata (the traditional belief in Waaqa or God), Islam, and Christianity.

Gragg (1976:173) identifies three dialects of the Oromo language. They are those of western group (including Wellegga), eastern group (especially Harar) and southern group (e.g. Borana). The present study is focuses on Harar Oromo which is spoken in eastern Ethiopia.

Oromo, a widely spoken language in Ethiopia, is also the major language in the horn of Africa. The language is spoken predominantly in Ethiopia, but also in Kenya and Somalia. Oromo has different official functions in the Oromiya regional state and in Oromiya zone of the Amhara region. It is a regional official language, a medium of instruction in primary schools and in teacher training institutions (colleges). It is also a field of study in different higher educational institutions such as Addis Ababa University, Jimma University, and Haramaya University etc. Furthermore, it serves as a language of the court, religion, and mass media.

\section{CONCEPTUAL FRAMEWORK}

\section{The Syllable in Generative Phonology}

In the early development of generative phonology phonological representation used to consider as consisting only linear strings of segments with no hierarchical structure unlike, the syntactic phrasal structure. In the Sound Pattern of English of Chomsky and Halle (1968) syllable structure had no role in the phonological organization. Regarding this, Anderson (1985:347) comments that, the syllable structure in the early generative phonology consisted of linear strings of segments with no hierarchical organization.

Developments in phonological theories motivated renewed interest in the syllable. Clements and Keyser (1983) generalize the factors that cause innovation in the following terms.

In our view, innovations in scientific theories involve two factors. The first is the identification of serious empirical inadequacies in the current research paradigm. The second is the perhaps independent development of new models which offer the possibility of treating well-known problems from a new perspective. (1983:1) 


\section{The Syllable and Syllable Structure}

\section{Definition of Syllable}

Katamba (1989:153) defines the syllable as: "It is the unit in terms of which phonological systems are organized. It is a purely phonological entity."

According to Hyman (1989:188), there are three basic questions that should be addressed with respect to the syllable.

1) How does one define the syllable?

2) How does one determine the syllable boundaries?

3) Is the syllable a necessary concept?

According to Blevins (1996:207) "The syllable...is the phonological unit which organizes segmental melodies in terms of sonority."

This means, the syllable is a phonological structure consisting of such parts as nucleus and, if any, onset and coda as well as suprasegmental features.

\section{Internal Structure of the Syllable}

The internal structure of the syllable has been the most debatable notion in the phonological theory. For instance, one may look at: Hyman (1985), Hayes (1989), Clements and Keyser (1983), and Blevins (1996).

Regarding the syllable internal structure, phonologists proposed several models. For instance, Blevins (1996:212) has listed the following five models of representing syllable structure.

I. Flat Structure: Does not have sub constitution but the segments themselves.

(1)
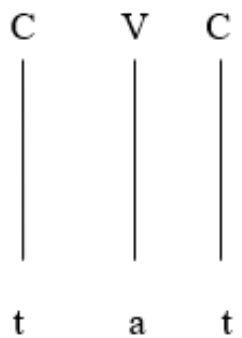

II. Moraic Approach: $\sigma \longrightarrow \mathrm{C} \mu(\mu) \mathrm{C}$

(2)

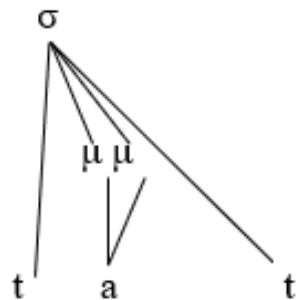

III. Binary Branching with Body: $\sigma \longrightarrow$ Body Coda; Body $\longrightarrow$ Onset Nucleus

(3)

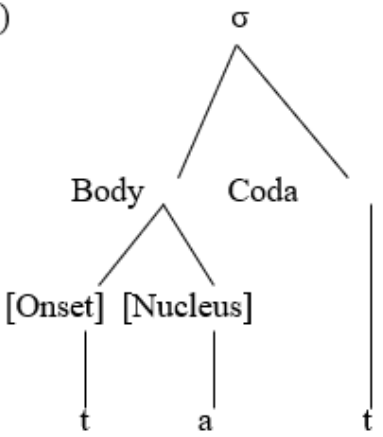

IV. Binary Branching with Rime: $\sigma \longrightarrow$ Onset Rime; Rime $\longrightarrow$ Nucleus Coda 


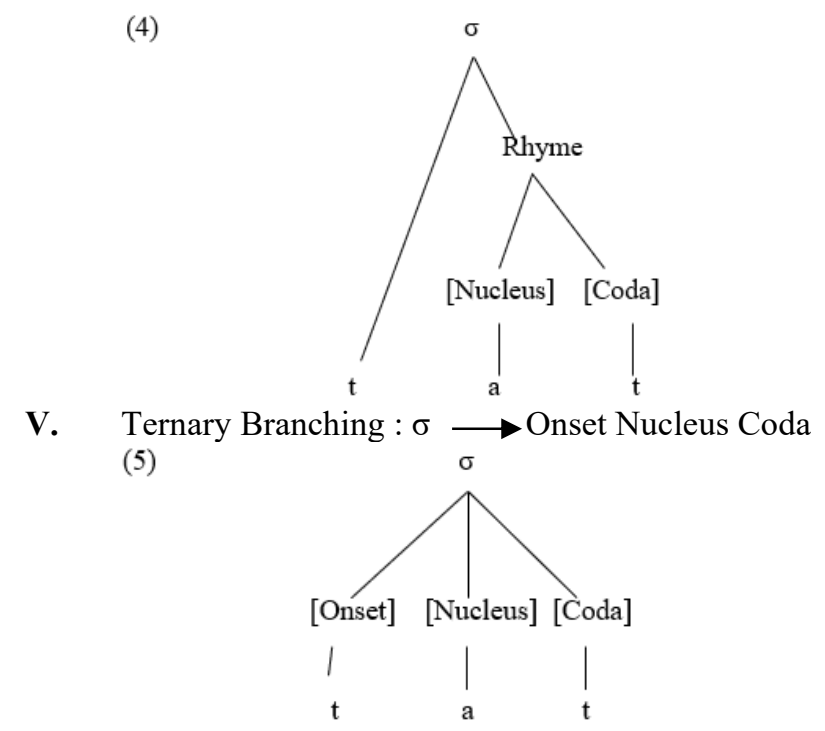

Of the above five syllable-internal structure models, the present research is based on the moraic model to determine the basic syllable structures of Harar Oromo.

\section{Function of Syllable Structure}

Kenstowicz (1994:250) forwards some justifications concerning the roles of syllable structure:

Phonological rules are often more simply and insightfully expressed if they explicitly refer to the syllable, several phonological processes are best interpreted as methods to ensure that the strings of phonological elements are parsable into syllable and the syllable is a natural domain for the statement of many phonotactic constraints.

In addition to Kenstowicz's (1994) justifications, Fudge (2001:25) pointes out the function of syllable by saying that the syllable is very important to provide a basis for prosodic distinctive features and to account for constraints on possible phoneme sequences.

\section{The Moraic Theory of Syllable Structure}

Mora is a term traditionally used refer to a minimal unit of metrical time or weight. It is now used as a separate level of phonological representation in some non-linear models of phonology (Crystal 1997:248).

In the moraic theory the only element principal between the syllable node and segmental node is called Mora. The Moraic approach of the syllable was first formalized in Hyman (1985) and further developed in Hayes (1989). In the Moraic approach, the syllable may contain one or more moras $(\mu)$.

Hayes (1989:254) states that generally languages treat syllables with long vowels or that are closed as heavy; whereas they consider syllables with short vowels and those that are open as light. This means, a heavy syllable contains two or more moras $(\mu \mu)$ while a light syllable consists of one mora $(\mu)$.

In addition to the above representation, Hayes (1989:254) proposes in his article, depending on the notion of heavy and light syllable, the moraic model in the following ways:

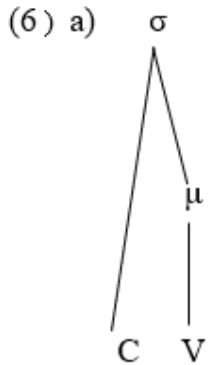

(CV)

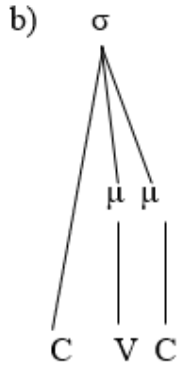

$(\mathrm{CVC}(\mathrm{C})$ c)

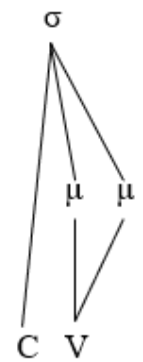

(CVV)

According to (a) above, a short vowel follows a consonant constituting an open syllable which is in terms of weight a light syllable. In (b), the syllable has a coda and is thus a closed syllable. However, the coda if followed by another consonant which makes the syllable heavy. In the case of (c), which contains a long vowel, the syllable is heavy. 


\section{Onset}

A consonant preceding a vowel which acts as nucleus is the onset of the syllable. Onset consonants are attached directly to the syllable node. An onset consonant does not play a role in mora- bearing. This means, onset consonants can not be a factor in determining whether a syllable is heavy or light (Hayes (1989:254).

a)

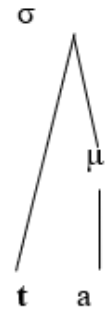

b)

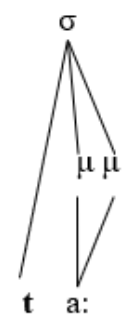

In bold (a) and (b), the first consonant /t/ is the onset.

\section{Nucleus}

The nucleus, in terms of sonority, is the peak of the syllable which is usually a vowel. In the moraic theory the nucleus is replaced by mora. In general, there are three models representing the syllable. These are the CV-tier model, the X-tier model and the Moraic model. The moraic representation is a better way of representing the syllable weight (Mulugeta 2001:7).

(8)

a) CV-tier model

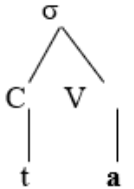

b) X-tier model

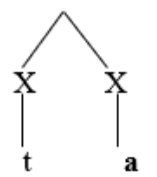

c) Moraic model

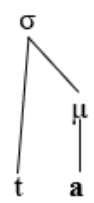

\section{Coda}

A consonant after the nucleus (vowel) in a syllable is called coda. A coda consonant can be a mora- bearing unit according to the rule of Weight-by-Position. Hayes (1989:258) indicates that in some languages coda consonants may not be mora- bearing. Because those languages may not apply the rule of Weight-by-Position. The following an example of a language which applies the Weight-by-Position rule.

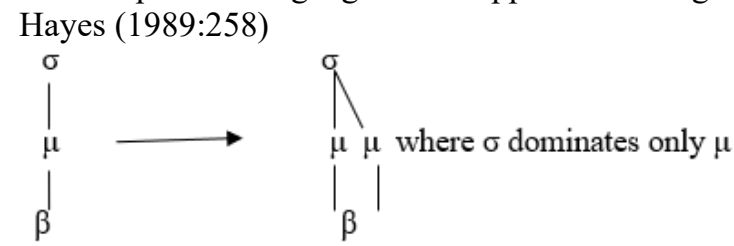

The following example illustrates that the onset consonant does not bear mora whereas the coda consonant does since with the assumption that it is followed by another consonant. This exemplifies the Weight-by-Position rule. Example: Hayes (1989:254)

(9)

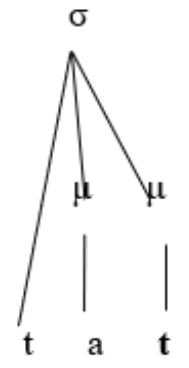

\section{The Rhyme}

The rhyme is what the nucleus and the coda together constitute in a syllable. The rhyme has no place in the moraic approach since the coda under the rhyme could or could not carry mora. 


\section{Mora}

As defined in 1.8.1.2, mora is a unit of sound used in phonology that determines syllable weight. Two moras define a heavy syllable while one mora is termed as light syllable.

The following are general assumptions about mora:

- An onset consonant does not bear a mora.

- The syllable nucleus is assigned one mora in the case of short vowel and long vowels assigned two morae

- Coda consonants are assigned a mora if the coda consonant is followed by another consonant in terms of a geminate or a cluster according to the Weight - by - Position rule.

To sum up, depending on a number of moras in the syllable structure, a mono- moraic syllable is light syllable while bi-moraic syllable is heavy syllable.

\section{Methodology of the Study}

The major tool for data gathering is field work. The data were collected, transcribed and analyzed. They were obtained from three sources:

- The researcher, as a native speaker of the language, used his competence in the study;

- Native speakers of the language were also interviewed.

- Works of various scholars on Oromo have been consulted.

\section{Syllable Structure in Harar Oromo}

In this chapter, first, the basic syllable types of Harar Oromo are presented. Then, the syllable template is discussed. Under this topic, the syllabification and the syllable internal structure of open and closed type syllables are presented. Then, the syllable structures are analyzed based on the moraic approach. Under the moraic analysis mono-moraic, bi-moraic and tri-moraic syllable types are presented. Finally, the syllable structures of nouns, adjectives and verbs are presented.

\section{Basic Syllable Types in Harar Oromo}

Regarding the syllable types of Oromo, my presentation is similar to Gragg (1976), Wako (1981), Habte (2003), Binyam (1988) and Owens (1985).

1- CV

$$
\begin{aligned}
& \text { a- /ga.na.ma/ 'mornig' } \\
& \text { CV.CV.CV } \\
& \text { b- /la.fa/ 'earth/ land' } \\
& \text { CV.CV } \\
& \text { c- /na.ga.ja/ 'peace' } \\
& \text { CV.CV.CV }
\end{aligned}
$$

\section{2- CVV}

$$
\begin{aligned}
& \text { a- /me:.Ja:/ 'material' } \\
& \text { CVV.CVV } \\
& \text { b- /ho:.la: / 'sheep' } \\
& \text { CVV.CVV } \\
& \text { c- /ba:.ti: / 'month' } \\
& \text { CVV.CV }
\end{aligned}
$$

3- CVC

$$
\begin{aligned}
& \text { a- /tak.ka/ 'one' (f.) } \\
& \text { CVC.CV } \\
& \text { b- /san.ga: / 'bull/ox' } \\
& \text { CVC.CV } \\
& \text { c- /gar.ga:r.sa/ 'help' } \\
& \text { CVC.CVVC.CV }
\end{aligned}
$$

\section{4- CVVC}

$$
\text { a- /Pob.bo:.le:t.ti:/ 'sister' }
$$

CVC.CV.CVVC.CV

b- /sad.de:t/ 'eight'

CVC.CVVC

Source: Researcher's own Survey (2011)

\section{Syllabification in Harar Oromo}

Syllabification is a process of assigning segments in a word to units of syllable length. Each language has its own 
syllable structure. The following are three steps by which words are segmented into syllables.

Step 1-Assign vowel to syllable nucleus

(1)

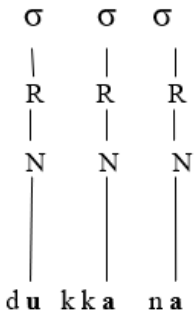

/dukkana/ 'darkness'

Step 2- Maximize initial consonant as Onset (extend directly to onset)

(2)

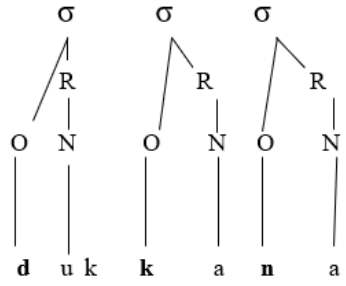

/dukkana/ 'darkness'

Step 3-Associate the remaining consonants to codas

(3)

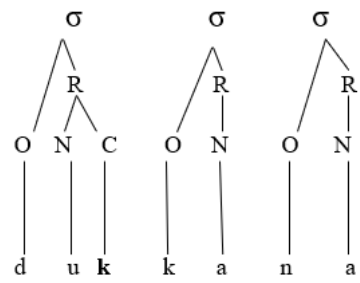

dukkana/ 'darkness'

Source: Researcher's own Survey (2011)

\section{The Syllable Template of Oromo}

With regard the syllable-internal structure of Oromo, there seems to be a discrepancy in approach between some researchers. For instance, according to Wako (1981:37) onset is an obligatory constituent in the syllable structure while, Beniyam (1988:18) indicates that onset and coda are optional constituents except the nucleus. However, following Wako (1981), I support and argue that an onset is an obligatory constituent. As pointed out earlier, the reason why a syllable appears to be beginning with a vowel is due to the fact that an underlying onset glottal plosive gets deleted in the surface representation. This means, word initial cluster is impermissible in Oromo. Similarly, only one consonant element occurs as a coda. To generalize, both an onset and a nucleus are obligatory while a coda consonant is optional.

Based on the above description, the syllable template that suits Harar Oromo is the following one.

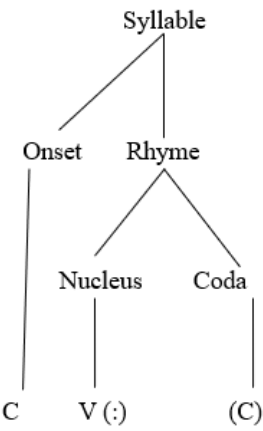

What has been summarized in the template may be interpreted as: CV, CVV, CVC, and CVVC. The preceding four syllable types embodied in the template are the syllable types found in Harar Oromo.

\section{Internal Structures of 'Open' and 'Closed' Syllables}

The syllable may be open or closed based on the structure of the rhyme. According to Hyman (1985: 189) the syllable that has no coda element is considered an open syllable whereas the syllable that has a coda element is 
termed as a closed syllable. That is, a syllable with no coda element is CV, while a syllable with a coda element is CVC. While the former without a final C (without a coda) is open, the latter with a final C (with a coda) is closed. The following examples from the language illustrate the structure.

\section{Open Syllable}
a. /ga.na.ma/ 'morning' CV.CV.CV
b. /du.ra/ 'first' CV.CV
c. /du.re:.sa/ 'rich' (m.) CV.CV:.CV

Source: Researcher's own Survey (2011)

All the preceding words consist of open syllables. Below is the structure of an open syllable.

(5)

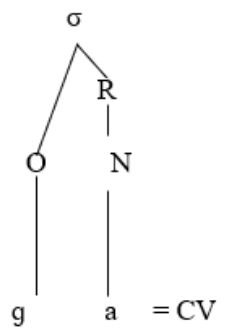

Source: Researcher's own Survey (2011)

The above syllable structure consists of only an onset and nucleus. In other words, it does not have a coda. Therefore, it is an open syllable. Below are examples of closed syllables.

\section{Closed Syllable}
a. /bak.ka/ 'place'
CVC.CV
b. /dzil.ba/ 'knee'
CVC.CV
c. / k'ul.k'ul.lu:/ 'clean'
CVC.CVC.CV

Source: Researcher's own Survey (2011)

In above examples, the syllables in bold are closed. Apart from an onset and a nucleus they consist of a coda. Therefore, they are closed syllables. Below is the structure of a closed syllable.

(6)

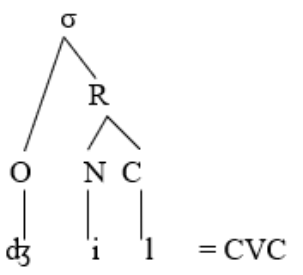

Source: Researcher's own Survey (2011)

\section{Moraic Analysis}

In this section, the moraic concept in connection to Harar Oromo syllable is discussed. In the moraic theory, the only principal element between the syllable node and the segmental node is the mora. In this respect, the syllable contains neither an onset nor a rhyme (Hayes 1989:254). However, the syllable contains one or more moras. It is the vowel in the syllable that is basically considered as a mora. That is, a short vowel has the value of one mora while a long vowel is worth two moras. Apart from a vowel a consonant can be given a mora value if it is followed by another consonant as in geminates and clusters. Similarly, a vowel that follows a sonority peak and is not parsed in the following an onset can constitute a second mora in a syllable. Below are given Harar Oromo words with mono-moraic, bi-moraic and tri-moraic syllables.

1. Mono-moraic Syllable (each short vowel has one mora $(\mu)$ ) 
(7)

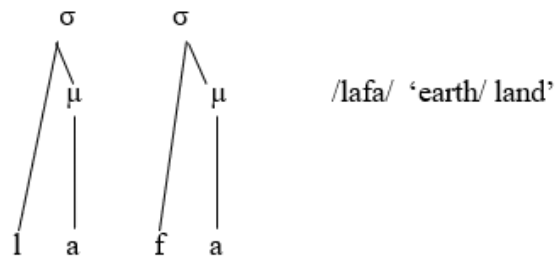

Source: Researcher's own Survey (2011)

In the above diagrammatical representation, there are two syllables in the word /lafa/ 'earth/ land'. Each CV syllable has a short vowel which has the value of one mora. Such a syllable is referred to as a mono-moraic syllable.

2. Bi-moraic Syllable (Long vowels have two moras $(\mu \mu)$

(8)

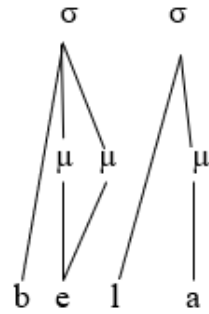

/be:la/ 'hunger'

In the above representation, the long vowel /e: / bears two moras. Thus, long vowels constitute a bi-moraic syllable. 3. Tri-moraic Syllables $(\mu \mu \mu)$

(9)

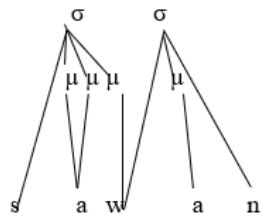

/sa:wwan/ 'cows' Source: Researcher's own Survey (2011)

In example above, in the first syllable vowel /a/ is long and has the value of two moras. In addition, the coda /w/ of the syllable is followed by another /w/ which forms the onset of the second syllable. The coda of the first syllable, therefore, assumes a mora value. Taking the two moras of the vowel of the syllable and one mora of its coda into account, the first syllable is tri-moraic.

Apart from geminates, consonant clusters could also set the condition for a coda consonant to have a mora value. This is illustrated by the example below.

(10)

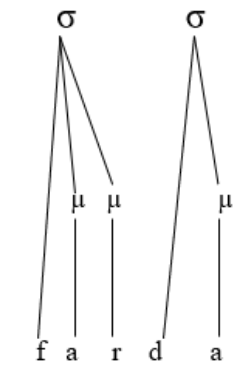

/farda/ 'horse'

Source: Researcher's own Survey (2011)

The example above shows that as in geminates, the first consonant of the clustering segments bears one mora. That is, of the cluster - $r d$ - the first $/ r$ is parsed as coda of the first syllable and since it is followed by another consonant/d/ it bears a mora value.

\section{Syllable Structure of Nouns, Adjectives and Verbs}

In this section, the syllable structure of nouns, verbs and adjectives of Harar Oromo are examined based on the moraic approach.

\section{Syllable Structure of Nouns}

The number of syllables in the nouns of Harar Oromo are varied. The moraic structure of nouns are also varied. Depending on segmental constituency a syllable may be heavy or light. A syllable with just a short vowel or followed by a coda of a single consonant has a length of one mora. It is therefore a light syllable. On the other hand, a syllable with a long vowel, a short vowel and a consonant with a mora value, that is, a bi-moraic syllable, 
is considered heavy. Syllables with additional mora may also be considered heavy or superheavy. (Crystal 1997:417).

1. Light-Light Syllable Sequence (mono-moraic syllable $(\mathrm{C} \mu . \mathrm{C} \mu)$

(11)

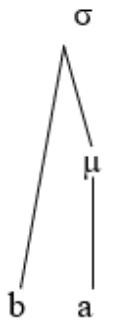

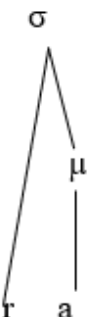

/bara/ 'year'

In the above representation of the noun /bara/ 'year', each syllable is light (mono-moraic). That is, each syllable has $\mathrm{C} \mu$ shape.

2. Light-Heavy syllable Sequence $(\mathrm{C} \mu . \mathrm{C} \mu \mu)$

(12)

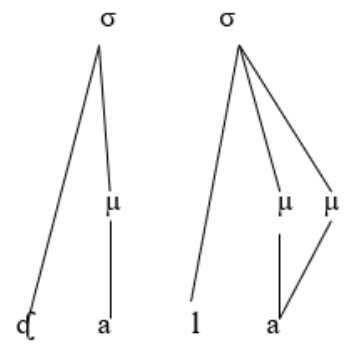

/dạla:/ 'female'

In the above structure, the arrangement of the syllables is $\mathrm{C} \mu-\mathrm{C} \mu \mu$. The first syllable with a single mora is light whereas the second syllable with two moras is heavy. Therefore, the pattern of the syllables in the noun is lightheavy.

\section{Light-Heavy-Light Syllable Sequence $(\mathrm{C \mu} . \mathrm{C \mu \mu .С \mu )}$}

(13)
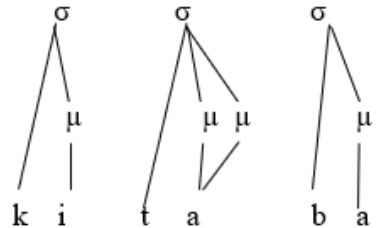

/kita:ba/ 'book'

In the noun /kita:ba/ 'book', the first and the last syllables are mono-moraic and light $(\mathrm{C} \mu)$. But the second syllable is bi-moraic $(\mathrm{C} \mu \mu)$, due to the long vowel /a/ and is therefore heavy.

4. Heavy-Heavy Syllable Sequence $(\mathrm{C} \mu \mu . \mathrm{C} \mu \mu)$

(14)

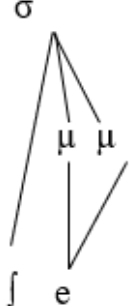

/ $\mathrm{e}$ :.ko:/ 'story'

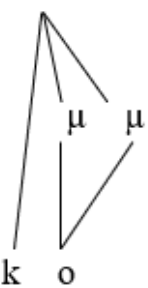

$\mathrm{k} \quad \mathrm{o}$

In the above noun, each syllable is bi-moraic and heavy as the result of the long vowels, /e: / and /o: / respectively. 


\section{5- Heavy-Light Syllable Sequence $(\mathrm{C} \mu \mu . \mathrm{C} \mu)$}

(15)

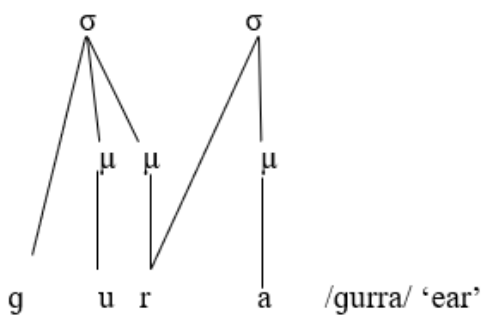

Researcher's own Survey (2011)

According the above moraic representation, the first syllable has two moras constituted from the short vowel $/ \mathrm{u} /$ and the coda $/ \mathrm{r} /$ which has a mora value since it is followed by another $/ \mathrm{r} /$ which caused gemination /-rr-/. In the syllable pattern of the word, the second $/ \mathrm{r} /$ is the onset of the second syllable /-ra/. In terms of the syllable weight, the first $(\mathrm{C} \mu \mu)$ is heavy while the second $(\mathrm{C} \mu)$ light. The noun if therefore heavy-light.

Oromo nouns, including those of the Harar dialect, use various plural suffixes: -o:ta, -wwan, -le:, -e:n and -a:n. In the following examples we examine the pluralizing process and the syllable structures in view of the moras they contain.

1- -o:ta

(16) a)
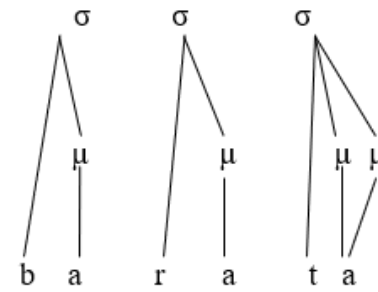

/barata: / 'student'

Researcher's own Survey (2011)

b)

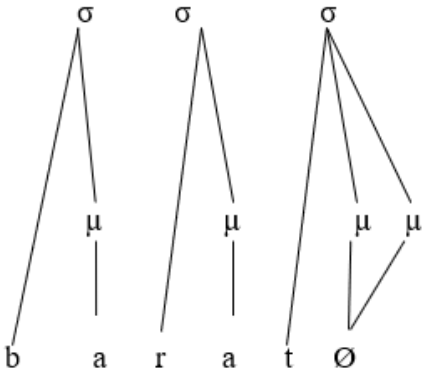

Deletion of the long vowel/a: /

Researcher's own Survey (2011)
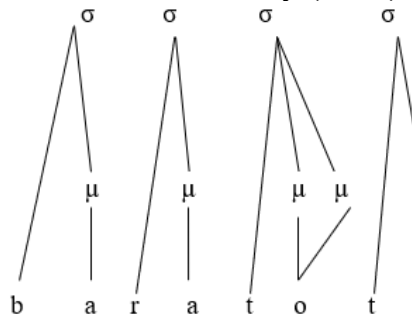

/barat-o:ta/ 'students'

Researcher's own Survey (2011)

The singular form of the noun /barata: / 'student' consists of three syllables with $\mathrm{C} \mu$.C $\mu$.C $\mu \mu$ moraic structure while the plural form /barat-o:ta/ 'students' consists four syllables with $C \mu . C \mu . C \mu \mu . C \mu$ moraic structure. 
2- -wwan

(17) a)

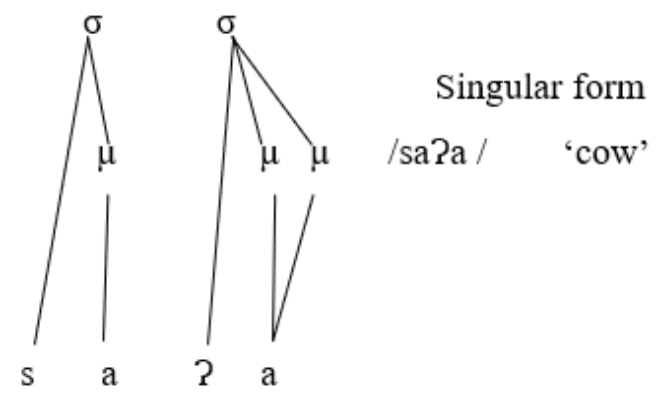

b)

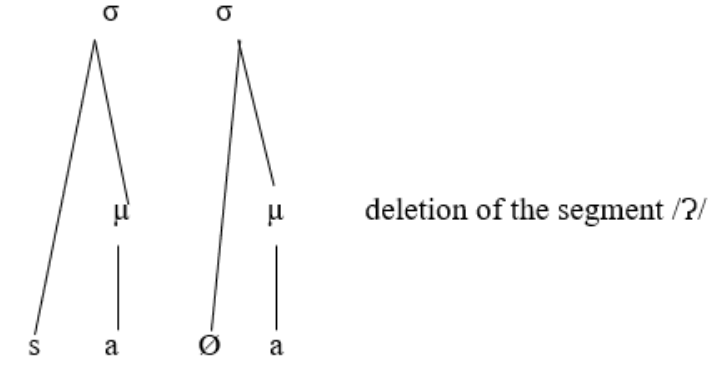

Researcher's own Survey (2011)

c)

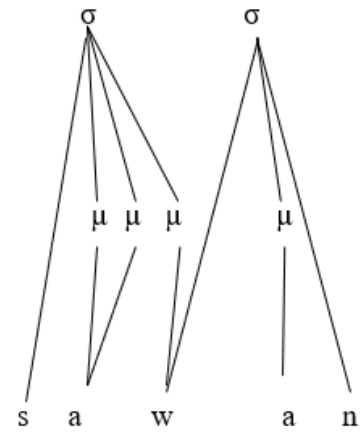

Plural form

Suffixing the plural morpheme -wwan

/sa:-wwan/ 'cows

Researcher's own Survey (2011)

In the above example the singular noun /sa Pa / 'cow' has a moraic structure of C $\mu$.C $\mu$ while it's plural /sa:-wwan/ 'cows form has $\mathrm{C} \mu \mu \mu . \mathrm{C} \mu$.

3. -le:

(18) a)

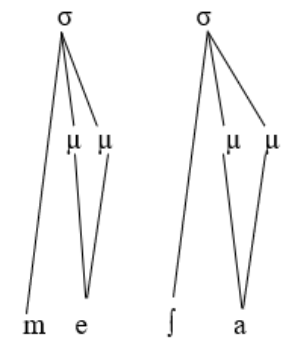

Singular form

/me:fa: / 'tool'

Researcher's own Survey (2011) 
b)

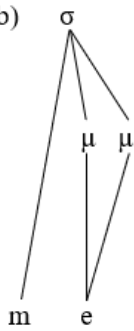

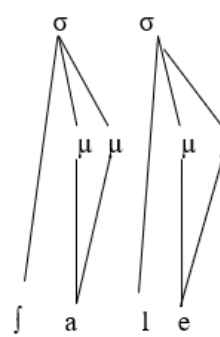

/me:fa:-le: / 'tools'
Plural form

Suffixing the plural morpheme-le:

Researcher's own Survey (2011)

In the above example the plural suffix is simply added without any process taking place in the singular form. The structure of the singular /me: $\int \mathrm{a}: /$ 'tool' is moraically C $\mu \mu . C \mu \mu$ whereas the plural /me:Ja:-le: /"tools' is С $\mu \mu . С \mu \mu . С \mu \mu$.

\section{4. -e:n}

(19) a)

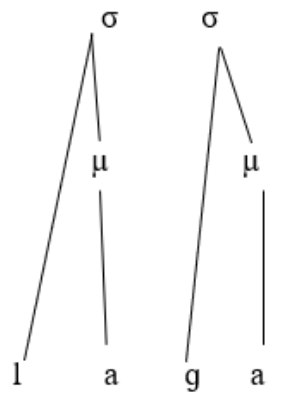

Singular form

/laga / 'river'

Researcher's own Survey (2011)

b)

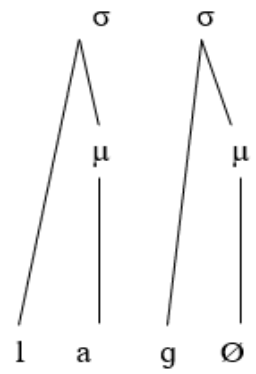

deletion of the final vowel /a/

Researcher's own Survey (2011)

c)

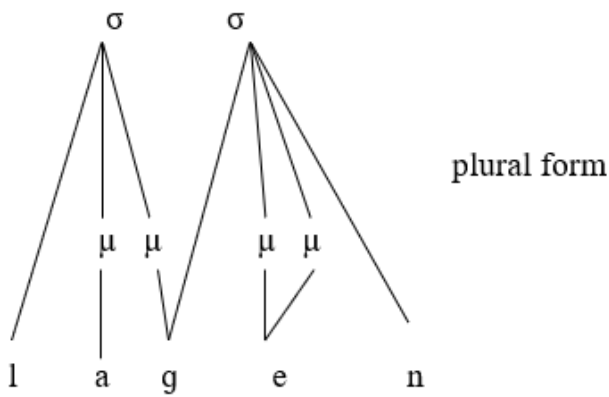

/lagg-e:n / 'rivers'

Gemination of the medial consonant /- gg-/ and suffixing the plural morpheme -e:n

Researcher's own Survey (2011)

In pluralizing /laga / 'river', first the final vowel /a/ is dropped and then the plural morpheme -e:n is suffixed /lagge:n / 'rivers'. Thus, the moraic structure comes out as $\mathrm{C} \mu \mu . \mathrm{C} \mu \mu \mathrm{C}$.

\section{The Syllable Structure of Adjectives}

Adjectives, in the language, agree in number with the nouns they modify. The plural form of most adjectives is constituted by partial reduplicating that is, the reduplication of the first syllable. If the first syllable is heavy, it is mostly simplified or reduced to light. For instance, the plural form of /di:ma: / 'red' (m.) is /di-ddi:ma:/ 'red' (pl., $\mathrm{m}$.) that is, the singular CV:CV: pattern changes to the plural CV- CCV:CV: pattern. Unlike the reduplicated from, 
the syllabification of the plural form appears as CVC.CV:CV: /did.di:.ma:/ 'red' (pl., m.). As for the moraic structure of the singular and plural form of the word, let us look at the example below.

(20) a)
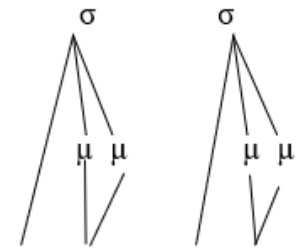

d i

$\mathrm{m}$ a

/di:ma: / 'red'

Researcher's own Survey (2011)

b)

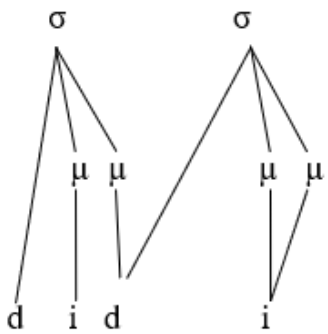

$\sigma$

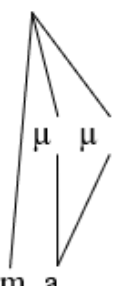

Researcher's own Survey (2011) /diddi:m-a:/ (m.) 'red' (pl.)

In the example above, the singular form /di:ma:/ 'red' has two heavy moras $(\mathrm{C} \mu \mu . \mathrm{C} \mu \mu)$ while the plural /diddi:ma:/ 'red' (pl.m.) has three heavy moras $(\mathrm{C} \mu \mu . \mathrm{C} \mu \mu . \mathrm{C} \mu \mu)$.

\section{The Syllable Structure of Verbs}

Harar Oromo verbs inflect for person, gender (in the third person singular), tense-aspect, mood, and voice as well as for negation. For instance, the verb /ga:fat-t-e/ 'she asked' is inflected for third person singular, feminine and perfective. It can be syllabified as /ga:.fat.te/. The verb consists of three syllables with the mora structure of $\mathrm{C} \mu \mu . \mathrm{C} \mu \mu . \mathrm{C} \mu$. In terms of syllable weight the first two syllables are heavy while the last one is light.

(21)

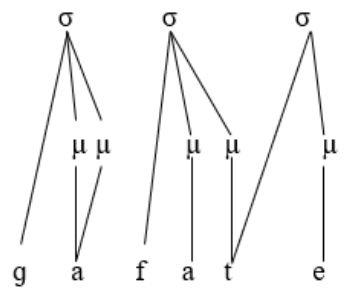

/ga:fat-t-e/ 'she asked'

Researcher's own Survey (2011)

The negative form of the above verb is structured as /hin-ga:fan-n-e/. But the structure is not inflected for person and could, therefore, be applied to any person provided it is preceded by the required personal pronoun. Thus, the verbal form which means 'she did not ask' is / isi:n hin- ga:fan-n-e/ ( isi:n 'she' hin- ga:fan-n-e 'did not ask'). The first $-n$ - in the verb stem is the result of the assimilation of -t- by the $-n$ - that follows it (ga:fat-n-e $>$ ga:fan-n-e). The syllable structure of the negative verb stem, hin-ga:fan-n-e is: hin. ga: fan. ne. Moraically it consists four syllables; the first three heavy and the fourth one light $(\mathrm{C} \mu \mu . \mathrm{C} \mu \mu . \mathrm{C} \mu \mu . \mathrm{C} \mu)$. Below is the diagrammatical representation.

(22)
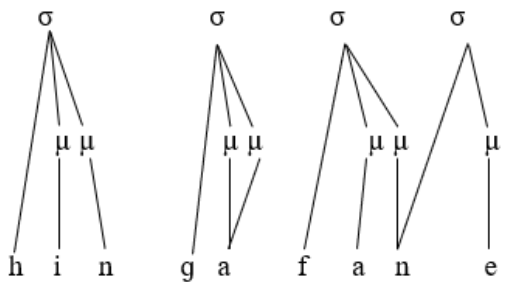

Researcher's own Survey (2011)

/hin-ga:fan-n-e/ 'did not ask' 
In this chapter, first, the syllable types of Oromo were identified: CV, CVV, CVC and CVVC. They are all based on the syllable template $\mathrm{C} \mathrm{V(:)} \mathrm{(C).} \mathrm{Distinction} \mathrm{has} \mathrm{also} \mathrm{been} \mathrm{made} \mathrm{between} \mathrm{open} \mathrm{and} \mathrm{closed} \mathrm{syllable.} \mathrm{While} \mathrm{the}$ former has no coda the latter does. Apart from the preceding important issues, most of the chapter has been devoted to moraic analysis. Accordingly, words were syllabified; syllables were assigned moraic value and were diagrammatically represented. These were thoroughly discussed based on examples from Harar Oromo. The next chapter deals with some syllable related phonological processes in Harar Oromo.

\section{Conclusion}

The thesis discusses two major issues pertaining to Harar Oromo: syllable structure and syllable based phonological processes. The moraic approach is employed to deal with the syllable structure. As opposed to other models like CV skeleton and X skeleton, I found this model to best represent syllable structure.

The thesis is organized around five chapters including this one. Chapter one, treats background issues, reviews of previous related studies and sets the structure of the thesis. It provides the objectives, the theoretical framework and the methodology of the study.

Chapter two revisits the segmental phoneme of Oromo (Harar Oromo) while chapter three presents the syllable structure of Harar Oromo. In the latter syllable-internal structures, syllabification, basic syllable types and moraic structures are analyzed and discussed. Furthermore, the syllable structures of nouns, adjectives, and verbs of Harar Oromo are dealt with.

In chapter four, I examine some syllable related phonological processes in Harar Oromo from the viewpoint of the moraic approach. Accordingly, such phonological processes as assimilation, deletion and epenthesis.

The syllable - internal structure of Harar Oromo can be handled by the C V(:) (C) template. This means, in the syllables of Oromo the onset and the nucleus are obligatory constituents whereas the coda is optional. The nucleus can also be optionally short or long. Beniyam (1988:18) suggests that both the onset and the coda are optional constituents in Oromo. For him, words like /adi: / 'white', /afur/ 'four' and /onne: / 'heart' do not have onset constituent. However, the present study underlines that underlyingly such words as the preceding ones begin with a glottal plosive / $/$ / which disappears in the surface representation. Therefore, the words are underlyingly represented as /Padi: / 'white', /Pafur/ 'four' and /Ponne: / 'heart'. In addition, related to an onset and coda, the language does not permit gemination in the two positions. However, word medially, a cluster of two consonants is permissible.

The basic syllable types of Harar Oromo, as in Oromo in general, are CV, CVV, CVC, and CVVC. The language treats $\mathrm{CV}$ and $\mathrm{CVC}$ syllables as light or mono-moraic. However, according to the Weight-by-Position rule, if the final $\mathrm{C}$ of the $\mathrm{CVC}$ is followed by another $\mathrm{C}$ it can have a mora value. This means, if a consonant is followed by an onset consonant of another syllable, it could bear weight. Fore example, /farda/ 'horse' can be syllabified as CVC.CV. In this word, the coda of the first syllable /far-/, that is $/ \mathrm{r} / \mathrm{bears}$ one mora because it is followed by the consonant onset of the following syllable /-da/. Hence, the moraic representation of the syllable /far-/ (CVC) would be C $\mu \mu$. A word with a gemination behaves in the same manner. For instance, the word /gudda: / 'big' can be syllabified as CV.CV: and moraically structured as $\mathrm{C} \mu \mu . \mathrm{C} \mu \mu$. That is, the coda of the first syllable bears mora since it is followed by another consonant, the onset of the next syllable.

As indicated above, one of the major topics deals with in the thesis concerns phonological processes; among them assimilation, deletion and epenthesis. In the case of assimilation, both total and partial types have been treated. For instance, in the change from the underlying word /sonba/ 'lung' to its surface form [somba] 'lung' partial assimilation is involved. That is the bilabial plosive $/ \mathrm{b} /$ regressively lends its labial feature to $/ \mathrm{n} /$ and thus the latter changes to $/ \mathrm{m} /$. This is what is known as partial assimilation. On the other hand, in changing the underlying form of /barna/ 'we learn' to its surface form [barra] 'we learn', totally assimilation is observed; that is, /r/ progressively assimilates $/ \mathrm{n} /$ totally and the latter becomes $/ \mathrm{r} /$.

Concerning deletion, the disappearance of the glottal plosive / $/$ word initially in the surface representation of such a word as (?)adi: 'white' is a good example. Like consonants vowel could also be deleted. For example, in the process of forming the plural of the word /nama/ 'man, person' as illustrated in the following representation: /nama/ 'man, person'/namØ/ /nam-o:ta/ 'men', people'. In this process, /a/ is deleted before the plural morpheme -o:ta/ is suffixed.

\section{References}

Abera Nefa. 1988. Long Vowel in Oromo. Unpublished M.A. Thesis. Addis Ababa University. Anderson, Stephen R. 1985. Phonology in the Twentieth Century. Chicago: The University of Chicago Press. Bender, M.L. and Mulugeta Eteffa. 1976. Galla. In Bender, M.L., I.D. Bowen, R.L. Cooper and C.A. Ferguson. Language in Ethiopia. London: Oxford University Press, page?

Beniyam Abebe. 1988. The Phonology of Raya Oromo. Unpublished M.A. Thesis. Addis Ababa University. Blevins, J. 1996. The Syllable in Phonological Theory. In Goldsmith, John A. (ed.) Handbook of Phonological Theory, Oxford: Blackwell, 206-245 
Carr, P. 1993. Phonology. Basingstoke: Macmillan. . 2008. A Glossary of Phonology. Edinburgh: Edinburgh University.

Chomsky, N. and M. Halle. 1968. The Sound Pattern of English. New York: Harper and Row.

Clark, J and C. Yallop. 1995. An Introduction to Phonetics and Phonology. $2^{\text {nd }}$ ed. Cambridge, Mass: Blackwell.

Clements, G.N. and J. Keyser. 1983. CV Phonology: A generative theory of the syllable. Cambridge, Mass: MIT Press.

Crystal, D. 1991. A Dictionary of Linguistics and Phonetics. Oxford: Blackwell.

1997. The Cambridge Encyclopedia of Language. $2^{\text {nd }}$ ed. Cambridge: Cambridge University Press. 1997. A Dictionary of linguistics and Phonetics. Oxford: Blackwell Publisher Ltd.

Davenport, M. and J. Hannah's. 2005. Introducing Phonetics and Phonology. $2^{\text {nd }}$ ed. London: Hodder Arnold.

Durand, Jacques. 1990. Generative and Non-linear Phonology. London: Longmans.

Fudge, E.C. 1984. English Word-Stress. London: George Allen and Unwin.

2001. The Syllable. In Charles W. Krediler (ed.) Phonology: Critical Concepts, New York: Routledge, 24-60.

Giegerich, H.J. 1992. English Phonology: An Introduction. Cambridge: Cambridge University Press.

Goldsmith, J. 1990. Auto- segmental and Metrical Phonology. Cambridge: Black Well.

Gragg, G. 1976. Oromo of Wellega. In Bender (ed.) the Non-Semitic Languages of Ethiopia. East Lansing, MSU Press, 166-195 1982. Oromo - English Dictionary. Michigan: Michigan State University.

Gussenhoven, C. and H. Jacops. 1998. Understanding Phonology. Great Britain.

Habte Bulti. 2003. Analysis of Tone in Oromo. Unpublished M.A. Thesis. Addis Ababa University.

Hayes, B.1989. Compensatory Lengthening in Moraic Phonology, Linguistic Inquiry, 20,253-306.

Hyman, L. 1985. A Theory of Phonological Weight. Dordrecht: Foris Publication.

Ito, J. 1988. Syllable Theory in Prosodic Phonology. New York: Garland.

Kahn, D. 1976. Syllable-based generalization in English phonology. Cambridge, Mass: MIT Ph.D. dissertation. Distributed by Indiana University Club.

Katamba, F. 1989. An Introduction to Phonology. London: Longman.

Kebede Hordofa. 1994. Baate (Wello) Oromo Phonology. Unpublished M.A. Thesis. Addis Ababa University.

Kenstowicz, M. 1994. Phonology in Generative Grammar. Cambridge: Blackwell.

Kiparsky, P. 1885. Some Consequences of Lexical Phonology. Phonology Year book. 2,83-136.

Ladefeged, P. 1975. A Course in Phonetics. Los Angeles: California University Press.

Lamontagne, G.A. 1993. Syllabification and Consonant Occurrences. Unpublished Ph.D. dissertation. University of Massachusetts.

Liberman, M. 1979. The Intonational System of English. New York: Garland.

Lloret Maria-Rosa.1988. Gemination and Vowel Length in Oromo Morphophonology. Ph.D. dissertation. Indiana University, Bloomington, Indiana.

Matthews, P.H. 2007. Oxford Concise Dictionary of Linguistics. Oxford: Oxford University Press.

McCarthy, J. and A. Price. 1990. Prosodic Morphology and Templatic Morphology. In Eid M. and J. McCarthy (eds.), Perspectives on Arabic linguistics; papers from the second annual symposium on Arabic Linguistics, $1-54$.

1993. Prosodic Morphology. Handbook of Phonological Theory. Cambridge: Blackwell, 318-366.

Moreno, M.M. 1939. Grammatica Teorico-Pratica Della Lingua Galla. Milano.

Muhammad Mussa. 1983. The Morphophonemics of Oromo. Unpublished M.A. Thesis. Addis Ababa University.

Mulugeta Seyoum. 2001. The Syllable Structure and Syllabification in Amharic. Unpublished MPhil Thesis. Norwegian University, Trondheim.

O’Grady, W. and M. Dobrovolsky. 1987. Contemporary Linguistic Analysis: An Introduction. Toronto: Copp Clark Pitman Ltd.

Owens, J. 1985. A Grammar of Harar Oromo. Hamburg: Buske.

Roca, I. and W. Johnson. 1999. A Course in Phonology. Oxford: Blackwell.

Selkirk, E.O. 1984. Phonology and Syntax: The Relation Between Sound and Structure. Cambridge MA: MIT Press.

Steriade, D. 1988. Reduplication and Syllable Transfer in Sanskrit and Elsewhere. Phonology. 5.1, 73-155.

Wako Tola.1981. The Phonology of Oromo: Mecha Dialect. Unpublished M.A. Thesis. Addis Ababa University. 